\title{
Audible Vision: A New Developed Way for Deaf to Communicate.
}

\author{
Mohamed Mohsen Radwan El-Tanahy \\ Dakahlia STEM High School \\ Mit Ghamr, Dakahlia, Egypt \\ Mohamed.1319017@stemdakahlia.moe.edu.eg
}

\author{
Ahmed Mohamed Abdelghany Sherif \\ Dakahlia STEM High School \\ Mansoura, Dakahlia, Egypt \\ Ahmed.1319003@stemdakahlia.moe.edu.eg
}

\author{
Yahia Yasser Mahmoud Elnegeiry \\ Dakahlia STEM High School \\ New Damieta, Damieta, Egypt \\ Yahia.1319025@stemdakahlia.moe.edu.eg
}

DOI: 10.31364/SCIRJ/v9.i09.2021.P0921880

http://dx.doi.org/10.31364/SCIRJ/v9.i09.2021.P0921880

\begin{abstract}
In our lives, we find many deaf people who are suffering from their disability to communicate normally with the society. Unfortunately, caring for them is less than many challenges we found in on our way. Deaf people can hardly communicate with ordinary people, and this causes a big problem for their lives and their education as they only use signs to communicate. In 2018, World Health Organization found that deaf people make up more than 5 percent of the world's population, with 466 million. Especially in Egypt, the deaf in Egypt represents approximately 1.5 million people, not a tiny percent. As a result, this issue must be treated with a low-cost and efficient solution. Our Appropriate solution is smart developed glasses. We are using modern technology to display the human voices around deaf - as a form of writing- on an OLED display mounted within the body of the developed glasses. The whole system is connected to the mobile application to receive the voice from the speaker and send it, through Bluetooth $\mathrm{HCO5}$, to the system that converts the human voice into text using Google Voice Recognition API. The glasses have successfully met the design requirements (which are low price, high efficiency, Availability, and simplicity) and proved to be a reliable, practical solution for deaf people to communicate with the whole world and live their lives normally.
\end{abstract}

Index Terms- Deaf, Communication, Bluetooth HC05, Smart Glasses. (Key words)

Arduino Nano,

\section{INTRODUCTION}

In 2018, Deaf people made up more than 5 percent of the world's population, with a total population of 466 million (According to WHO data for 2018). Those who interact hard with the community communicate through sign language, which is not what everyone learns. The deaf in Egypt represents approximately 1.5 million people. Egypt is making in Egypt (HVIS) and also, signing a cooperation protocol between the Ministry of Solidarity and the Egyptian

Company for International Tourism Projects (Americana) to launch "New Life" to operate and train the deaf. These solutions are needed but not enough. We have to take care of them and do what we can to their advantage. So, our project aims to help the deaf by using a modern technique to display the human voices around them - as a form of writing- on an OLED display mounted within the body of the smart glasses. The project targets deaf people, especially their disability in communicating with the community and allowing the deaf to communicate with specific people by signs and communicate with the whole world. Our project offers a unique solution at an affordable price that is not like Google Glasses for businessmen; It's flawed by its high price (\$999) and its lack of availability in some countries in the Middle East compared with our solution that wouldn't exceed (\$40). Besides, it aims for a more luxurious life, but we aim to solve a societal problem that the whole world faces.

\author{
II. MATERIALS \\ 1. 0.96-inch I2C OLED Display \\ 2. Bluetooth Module HC-05 \\ 3. Arduino Nano \\ 4. lipo battery $3.7 \mathrm{~V} \& 800 \mathrm{mAh}$ \\ 5. Battery charger \\ 6. slide switch TSH \\ 7. $\mathrm{C}++$
}

Many efforts to provide care for them, such as E-Learning Support Program for Hearing and Visually Impaired Students 


\section{METHOD}

After completing the application and the device, we are ready to test our system based on the design requirements we have put into assuring that it is working probably without any drops in data gained or interruption in wires.

Test-plan is essential to see whether the project will function correctly or not and be modified to achieve suitable results. For that, we tested our project firstly, and there was not any problem. Then we tried to test it with many deaf people with an efficiency of $98 \%$, and after research, we compared our project to Google Glasses for people in business. It is flawed by its high price (\$999) and its lack of availability in some countries in the Middle East. Besides, it aims for a more luxurious life, but we aim to solve a societal problem that the whole world faces.

In this project, the methods varied between hardware and software methods. Each of them required accurate and hard work.

\section{For the Software, we did the following (Figure 1\&2):}

1. Searching for a suitable challenge and getting the idea of the project that helps deaf people.

Figure 1 shows the primary function, printing the text

2. Programming the application with

Arduino nano which connects between the prototype and the mobile application.

3. Testing the app to detect the syntax and logical errors that occurred in the code.

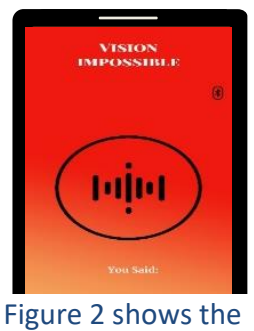

- For the hardware, we did the application interface. following (Figure 3\&4):

1. We have made a

3D design of a removable part that

Figure 1 shows how to connect between the prototype and the app.

any glasses can hold.

2. After finishing the code -which will be explained in the analysis- we connected all the wires between the Arduino, the Bluetooth module, and the LCD correctly.

3. We connected the Bluetooth module with the mobile application. Using the STT servers provided by Google Voice Recognition API, the voice will be transmitted to the I2c display in front of the user's eyes.

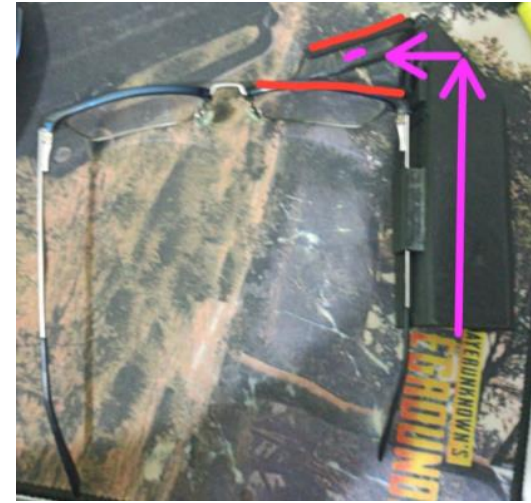

IV. ANALYSIS

\section{Software Part:}

Variables are the most crucial portion of the software. We must determine what the inputs and the outputs are. The main inputs are the speaker's voice, the mobile application,

Bluetooth, and Google Voice Recognition API. The main outputs are the smart glasses and the text printed on the IC2 OLED Display. These are our codes with explanations to clarify how our project works:

-The first three lines define the U8glib.h, which is responsible for dealing with the text. Then, there is a declaration for a variable that will store the text printed on the screen and represent it

Finclude $\langle$ Ugglib.h $\rangle$

String voice;

U8GLIB_SSD1306_128X64 u8g(U8G_I2C_OPT_NONE।U8G_I2C_OPT_DEV_0)

-The first part of the code controls the text's format: its color, size, and position.

-The second part is the primary function, which contains printing the text sent via Bluetooth HC05.

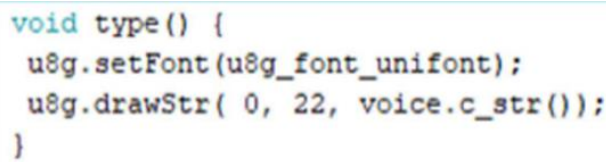

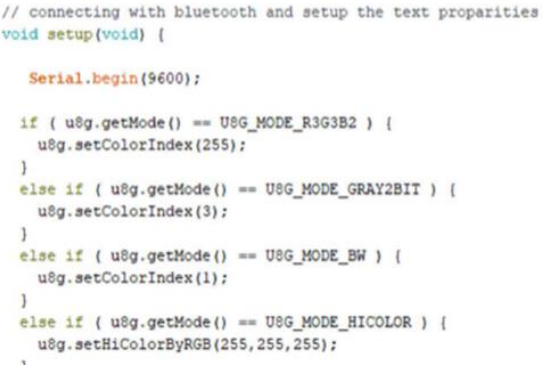


-The second part is the primary function, which contains printing the text sent via Bluetooth $\mathrm{HCO5}$

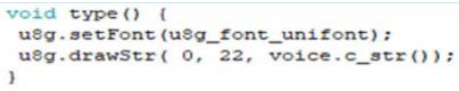

-The third part is about reading a specific variable sent from the application (its value is the words said) and making a continuous loop.

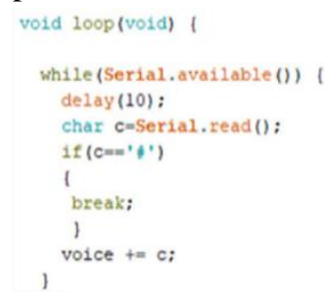

-Finally, while the application sent the text, its value will be declared to the variable by the first part of the code. After presenting the text on the screen, this variable will be cleared to store a new one.

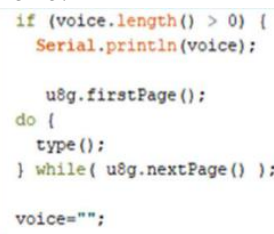

\section{Hardware Part:}

Our mobile application correlates with a hardware prototype to get text information about what the speaker wants to say, and this will make the deaf communicate with everyone easily. The prototype is simply smart glasses with an IC2 OLED Display. Our prototype is based on many primary components to get the data:

- 0.96-inch I2C OLED Display: It is based on a popular SSD 1306 display controller. It works on both I2C (TWI). It is small and has a resolution of $128 \times 64$ pixels. It is ideal for our project as we can display fonts of various sizes.

- Bluetooth Module HC-05: It can transmit and receive the data wirelessly between the mobile application and the smart glasses.

- Arduino Nano: It is used to produce a clock of precise frequency using constant voltage.

- Lipo Battery and Battery Charger.

- slide switch TSH: It helps us turn on or turn off our device whenever we want.

\section{How does it work?}

1/ Connect the Smart Glasses to the Mobile Application via Bluetooth module.

2/ Convert the human voice to text using Google Voice Recognition API.

3/ The Text will be printed on the IC2 OLED Display.

\section{Design requirements:}

- $\quad$ Low Price: Google Glasses for businessmen is flawed by its high price (\$999) and its lack of availability in

some countries in the Middle East. Besides, it aims for a more luxurious life, but we aim to solve a societal problem that the whole world faces.

- High Efficiency: It converts the voice into text on the screen with an accuracy of about $99 \%$.

- Availability: It is available for everyone because of its low price.

- Simplicity: we designed our application based as simply as possible, and it is suitable to be used efficiently for all ages. Thus, we prevented the users from being distracted or confused, and we made it very easy for the deaf to communicate with everyone.

\section{RESULTS}

We collected great results by testing the project on fifteen different people of different ages and genders from around the community and took their comments, opinions, and feelings about the idea and the project. They confirmed that it would be an excellent transfer in the lives of deaf people. We also took tremendous and valuable recommendations from the feedback that we will add to the out project in the future, God willing. After testing our project and taking the feedbacks, we found that it is unique with its features, mechanism, simplicity, availability, and low price. We can see that our project has achieved all the design requirements. We also found that it has high efficiency and accuracy. It depends on modern technology, especially IoT, which made it easy for all ages, especially older people. So, according to our test plan and results, we can say that our project has a significant role in helping deaf people communicate and deal with others straightforwardly and simple way.

\section{Conclusion}

Smart glasses are very impressive in many aspects that are concerned with the principle of helping the patients of our society and providing all possible means to make the deaf see like us by exploiting the techniques of modern technology to transform the speaker's voice into phrases that are printed on the screen in front of his eyes with high accuracy.

So, we could say that our project can solve a significant problem which is the disability of deaf people in communication with others, which makes them feel helpless in our community. So, we depended on the modern IoT technology as everyone today has a mobile phone. There is a feature in every mobile phone that can convert voice to text, which is google assistant or google voice searcher. We used this feature's API by making our project's hardware and software to make the text be displayed in front of their eyes so that they can communicate with others easily. In addition, our project works on three features: low cost, high efficiency, and it is easy for anyone to work with.

\section{ACKNOWLEDGMENT}

Behind this great work, some people certainly stood behind us and supported us after Exert a tremendous and continuous effort of work and research to bring the project out in this way.

After God's blessings, we want to thank Mohamed Abdelsatar and Amrawy (engineering students), in 
addition to Omar Emad (Programming and coding specialist), for the incredible support of the IoT contest administrators.

\section{REFERENCES}

[1]- Deafness and hearing loss. (2021, April 1). World Health Organization. https://www.who.int/newsroom/fact-sheets/detail/deafness-and-hearing-loss

[2]- Instructables. (2017, September 30). Connecting HC05 Bluetooth Module to Arduino. https://www.instructables.com/Connecting-HC05-Bluetooth-Module-to-Arduino/

[3]- Instructables. (2017a, September 29). How to Receive Arduino Sensor-Data on Your AndroidSmartphone. https://www.instructables.com/Howto-Receive-Arduino-Sensor-Data-on-YourAndroid/

[4]- Razer's new 'gaming glasses' have blue-light blocking properties and built-in earphones! (n.d.). Yanko Design. Retrieved July 4, 2021, from https://www.yankodesign.com/tag/smart-glasses/

[5]- Sullivan, D., \& Sullivan, D. (2017, May 17). Your guide to using Google Assistant and the Google search app on Android \& iPhone. Search Engine Land. https://searchengineland.com/googleassistant-guide-270312

[6] Valdellon, L. (2020, November 2). What Are the Different Types of Mobile Apps? And How Do You Choose? CleverTap. https://clevertap.com/blog/types-of-mobile-apps/ 